\title{
Structured Product Labeling Marketing Category
}

National Cancer Institute

\section{Source}

National Cancer Institute. Structured Product Labeling Marketing Category. NCI

Thesaurus. Code C73581.

A characteristic specifying a category for marketing a medicinal product. 